\title{
General practitioners' contribution to the management of community-acquired pneumonia in the Netherlands: a retrospective analysis of primary care, hospital, and national mortality databases with individual data linkage
}

\section{Bianca EP Snijders', Wim van der Hoek¹, Irina Stirbu², Marianne AB van der Sande ${ }^{1,3,}$ *Arianne B van Gageldonk-Lafeber ${ }^{1}$}

' Centre for Infectious Disease Control, National Institute for Public Health and the Environment, Bilthoven, The Netherlands ${ }^{2}$ NIVEL, Netherlands Institute of Health Services Research, Utrecht, The Netherlands

${ }^{3}$ Julius Center, University Medical Center, Utrecht, The Netherlands

Received 27th March 2013; revised 17th June 2013; accepted 27th June 2013; online 16th September 2013

\begin{abstract}
Background: Community-acquired pneumonia (CAP) is an important cause of hospital admission and death, but the extent of the problem of CAP at the primary healthcare level is largely unknown.

Aims: To investigate the contribution of general practitioners (GPs) to the management of patients with CAP in the Netherlands.

Methods: The study population consisted of all people enlisted in a GP network. We obtained information on CAP episodes from GP electronic records (using ICPC code R81) during the years 2002-2009. CAP registrations were also obtained from national hospital discharge data (ICD-9 codes) and cause of death statistics (ICD-10 codes). The three registration systems were linked at the individual level. We used descriptive analyses to estimate the annual number of CAP episodes (i.e. defined as a CAP diagnosis within 30 days).

Results: From 2002 to 2009 the mean annual size of the study population was 395,039. For this population, 3,700 (0.9\%) CAP episodes per year were registered in at least one of the registration systems, 2,933 (79\%) of which were in the GP system only. Recovery within 30 days occurred on average in 95\% $(2,791 / 2,933)$ of the CAP episodes annually registered by a GP, while $2.3 \%(67 / 2,933)$ of patients with a GP-registered CAP episode were admitted to hospital within 30 days and $1 \%(26 / 2,933)$ had a fatal outcome within 30 days. Conclusions: The vast majority of CAP episodes registered in the Netherlands are managed successfully at the GP level without hospitalisation.

(C) 2013 Primary Care Respiratory Society UK. All rights reserved.

BEP Snijders et al. Prim Care Respir J 2013; 22(4): 400-405

http://dx.doi.org/10.4104/pcrj.2013.00085
\end{abstract}

Keywords community acquired pneumonia, retrospective study, episodes, general practice, hospitalisation, mortality

See linked editorial by Infantino and Infantino on pg 383

The full version of this paper, with online appendices, is available online at www.thepcrj.org

\section{Introduction}

Community-acquired pneumonia (CAP) refers to pneumonia acquired outside of hospitals or extended care facilities.' It is a leading cause of illness, hospital admission, and death worldwide, mainly among young children and elderly persons..$^{2-4}$

Most studies on CAP have focused on hospitalised patients. However, the majority of patients diagnosed with CAP in the Netherlands are seen in a primary care setting. ${ }^{5}$ A study from the UK in 2006 found that hospital admission was needed for $20-40 \%$ of CAP patients and that the overall mortality from CAP was $5-10 \%{ }^{6}$ Focusing on hospitalised CAP may therefore conceal the real size of the public health burden caused by CAP.

In the Netherlands, general practitioners (GPs) have a gate-

\footnotetext{
* Corresponding author: Dr Arianne B van Gageldonk-Lafeber, Centre for Infectious Disease Control Netherlands, P.O. Box 1, 3720 BA Bilthoven, The Netherlands. Tel: +31 (0)30 2742063 Fax: +31 (0)30 2744409 E-mail: rianne.van.gageldonk@rivm.nl
} 
keeping role for specialised care. However, population-based data are limited and the extent of the problem of CAP at the primary healthcare level is largely unknown. Investigating the contribution of GPs to the management of patients with CAP might elucidate these knowledge gaps. In a previous ecological study we used three different datasets that did not necessarily consist of the same patients, ${ }^{5}$ hampering direct comparisons between the involvement of the different levels of care where CAP diagnoses are registered. In the current study we therefore build a dataset consisting of CAP registrations in a GP network linked to hospital discharge data and national cause of death statistics at the level of the individual.

The aim of the study was to determine the proportion of CAP episodes at the GP level, the hospital level, and at national death registration level and to obtain insight into the pathways between these three levels.

\section{Methods}

\section{Study population}

We conducted a retrospective study based on patients registered in the Netherlands Information Network of General Practice (LINH) over the period 2002-2009.' The LINH network comprises an average of 85 GP practices (according to the latest update in 20107). The patient population accounts for about $2.6 \%$ of the Dutch population, representative with regard to age and gender. ${ }^{7}$ Patients with an unknown or invalid unique identifier number (i.e. unique code based on date of birth, postal code or gender) and patients from GP practices with poor registration (i.e. less than 24 weeks of registration per year) are excluded.?

\section{Data sources}

\section{General practice database}

The GP database of the LINH network contains records for each separate consultation, providing information which includes age, gender, suspected diagnoses, and date of consultation. These diagnoses are coded using the International Classification of Primary Care (ICPC). ${ }^{8}$ In addition, referrals and prescribed medications are recorded. The present study was restricted to GP consultations for the clinical diagnosis of pneumonia (defined as ICPC code R81).

\section{Hospital database}

The Hospital Discharge Register (LMR, National Medical Registry) $)^{9}$ contains information on admissions and discharge diagnoses of teaching and general hospitals in the Netherlands. Data include the demographic characteristics of the patient, diagnostic and therapeutic interventions, and principal and secondary diagnoses at hospital discharge coded by the International Classification of Diseases, 9th revision - Clinical Modification (ICD-9-CM) codes. ${ }^{10}$ For the present study, data were restricted to pneumonia as the principal or secondary discharge diagnoses defined by the ICD-9 $\operatorname{codes}^{10}$ listed in online Appendix 1, available online at www.thepcrj.org (including the cumulative frequencies over the period 2002-2009).

\section{Mortality database}

Details from death certificates issued for all deaths in the Netherlands are recorded in the cause of death registry maintained by Statistics Netherlands (CBS). ${ }^{11}$ For the present study, data were restricted to pneumonia as the primary or secondary cause of death defined by the ICD-10 codes $^{12}$ listed in online Appendix 2, available online at www.thepcrj.org (including the cumulative frequencies over the period 2002-2009).

\section{Individual data linkage}

All records of the three databases were individually linked to the Dutch population register (GBA) with respect to three variables (i.e. date of birth, postal code, and gender). If linkage was applied successfully, an (anonymous) unique identifier could be assigned to every registered patient with CAP. These unique identifiers enabled us to link the three different databases mutually, restricted to the GP (LINH) study population (Figure 1). The linkage of the three databases was performed for each calendar year separately as the study population varied per year.

\section{Data analysis}

We defined a new CAP episode as (1) a diagnosis of CAP made by an attending GP which was not preceded by a GP diagnosis of CAP in the 30 days before; or (2) a discharge diagnosis of CAP registered in the hospital database. A patient can have more than one GP consultation or hospital admission for the same CAP episode, so we

\section{Figure 1. Origin of the study populations of patients} with community-acquired pneumonia (CAP) episodes (from 2002 to 2009). LINH=The Netherlands Information Network of General Practice

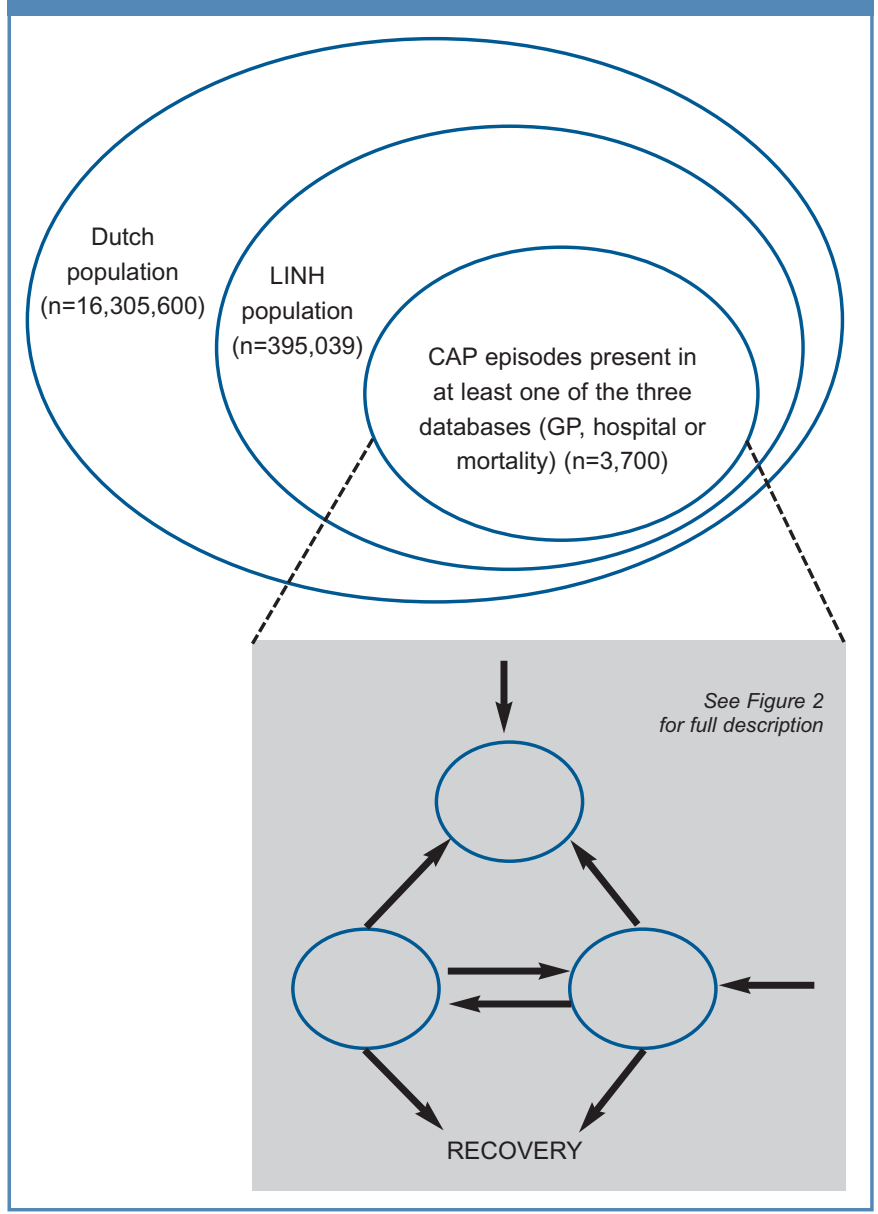


Figure 2. Flow chart of CAP episodes from 2002 to 2009

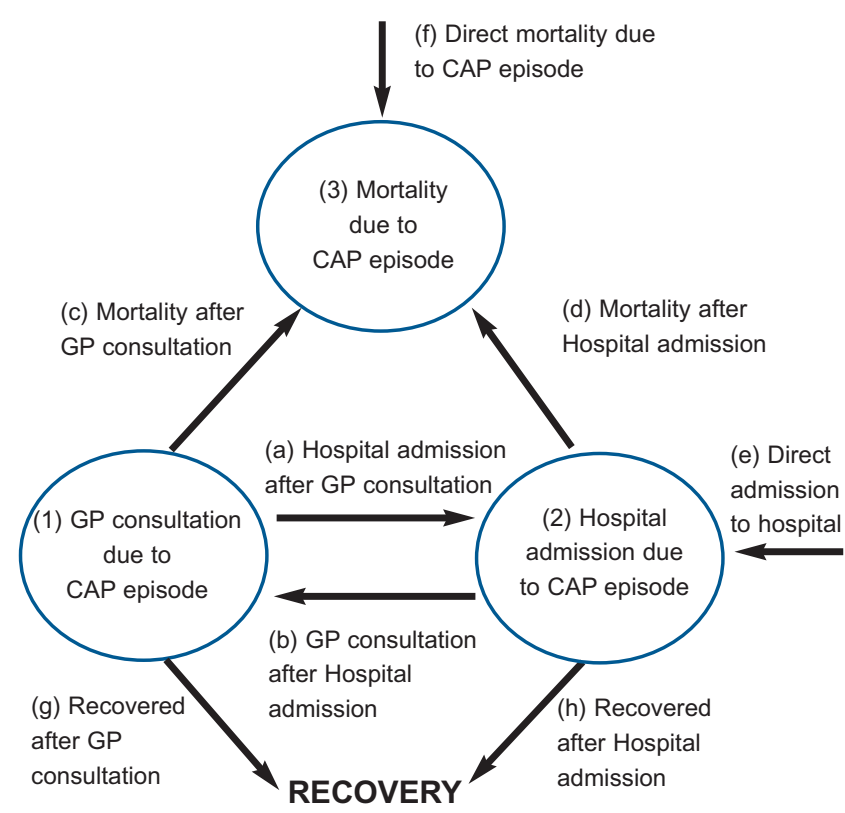

did not consider patients but CAP episodes. A diagnosis of CAP may be first registered in relation to a GP consultation, a hospital admission, or death. Hospital admissions occurring within 30 days after a registered GP consultation (or vice versa) were regarded as referrals. The annual incidence of CAP episodes was calculated as the total number of first CAP episodes (i.e. the first episode for an individual in a particular year) registered in one of the three databases (per year) divided by the total study population (per year) $\times 10,000$.

Figure 2 shows a flow chart of all stages of CAP episodes that were addressed in the present study. Descriptive statistics were used to analyse the mean number of CAP episodes from 2002 to 2009 (per year) at three different levels (i.e. databases): (1) GP consultation; (2) hospital admission; and (3) death (represented as circles in Figure 2). The number of CAP episodes registered in at least two databases provided us with information about the pathways of CAP episodes between the different levels (Figure 2, arrows (a-d) where (a) represents hospital admission after GP consultation, (b) indicates GP consultation after hospital admission, (c) indicates mortality after GP consultation, and (d) shows mortality after hospital admission). We assumed that CAP episodes only registered in the hospital database or only in the mortality database represent CAP episodes with direct admission to hospital and direct mortality (Figure 2, arrows (e) and (f), respectively). CAP episodes that were only present in the GP database assume "recovery" (Figure 2, arrow (g)). Assumed "recovery" after hospital admission was defined as presence in the hospital database without referral to a GP and without death thereafter (Figure 2, arrow (h)).

All statistical analyses were performed using SPSS 14.0 on the fingerprint-secured Remote Access facility of Statistics Netherlands. Dutch legislation allows linkage at the individual level by Statistics
Netherlands. However, it is obligatory that such output is checked by Statistics Netherlands and it must not be traceable to individuals. Therefore, numbers below 10 are reported as " $<10$ ". For age distributions we present the spread around the mean (SD) instead of the median with range as the maximum age could represent one individual, which could threaten patient confidentiality.

\section{Results}

The average annual size of the study population (i.e. patients enlisted at GP (LINH) practices) over the study period (2002-2009) was 595,026 . Each year approximately one-third of the records were not suitable for analysis (due to unknown/invalid identifier number or registered by GP practice with poor registration). The annual mean number of patients included in the present study was 395,039 (range 2002-2009: 325,218-464,371).

The crude pneumonia incidence from 2002 to 2009 ranged between 70 and 77 first episodes per 10,000 registered patients per year, with an outlier in 2005 (95 first episodes per 10,000 registered patients, Table 1).

On average, 3,700 new CAP episodes per year were registered (in at least one of the registration systems). The large majority $(2,933)$ of annual episodes were registered at the GP (Table 2). Patients registered at the GP were younger than those (also) registered at the hospital and those who (also) died (mean age 47, 57,78 years, respectively; Table 2 ).

\section{Primary care}

Of the mean 2,933 annual CAP episodes that were registered during a GP consultation, 50 had been admitted to hospital in the previous 30 days (Figure 3A). Of the remaining 2,883 episodes, 67 were hospitalised after GP consultation and 26 died. The large majority $(2,791 / 2,883 ; 97 \%)$ therefore recovered with GP management only.

\section{Hospital admissions}

Of the mean 602 annual CAP episodes registered at a hospital, 534 (89\%) were directly admitted without GP consultation (Figure 3B). Recovery within 30 days after hospitalisation occurred in the majority of CAP episodes (509/602; 84\%), while a GP consultation was reported within 30 days following discharge for $8 \%$ (50/602; Figure 3B). Of the CAP episodes registered during hospital admission, $7 \%$

\begin{tabular}{|c|c|c|c|}
\hline Year & $\begin{array}{l}\text { Number of first } \\
\text { CAP episodes* }\end{array}$ & $\begin{array}{l}\text { Study } \\
\text { population }\end{array}$ & $\begin{array}{l}\text { Incidence } \\
\text { per } 10,000\end{array}$ \\
\hline 2002 & 3138 & 433,968 & 72 \\
\hline 2003 & 2702 & 383,112 & 71 \\
\hline 2004 & 2327 & 330,856 & 70 \\
\hline 2005 & 3103 & 325,218 & 95 \\
\hline 2006 & 2681 & 347,654 & 77 \\
\hline 2007 & 3260 & 441,898 & 74 \\
\hline 2008 & 3302 & 433,231 & 76 \\
\hline 2009 & 3492 & 464,371 & 75 \\
\hline
\end{tabular}




Table 2. Mean annual number of community-acquired pneumonia (CAP) episodes in the study population (N=3,700)
from $\mathbf{2 0 0 2}$ to $\mathbf{2 0 0 9}$
\begin{tabular}{lllll} 
CAP episodes registered in GP electronic records & n/N & \%* & Sex (\% male) & Mean (SD) aget \\
\hline CAP episodes registered in hospital discharge data & $602 / 3,700$ & 16 & 57.6 & $57(28.5)$ to $52(26.9)$ \\
\hline CAP episodes registered in cause of death statistics & $301 / 3,700$ & 8 & 50.9 & to $61(24.8)$ \\
\hline
\end{tabular}
*Total does not add up to $100 \%$ as more than one (different) CAP episode(s) per year may occur. tRange per year (from 2002 to 2009). (12.9)

died within 30 days of discharge with pneumonia as the primary or secondary cause (43/602; Figure 3B). Of these 43 fatal CAP episodes registered in the mortality database after hospital admission, the mean age per year ranged from 74 to 80 years (SD 16.7-13.2).

\section{Mortality}

Seventy-seven percent (233/301) of the patients who died with pneumonia were not previously registered in the GP database or the hospital database (Figure 3C). A GP consultation was registered in the preceding 30 days for $9 \%$ (26/301) pneumonia deaths and for $14 \%$ (43/301) a preceding hospitalisation was registered (Figure 3C; figures and percentages do not add up due to rounding of the annual means).

\section{Discussion}

\section{Main findings}

This study is unique in investigating CAP episodes in the Netherlands
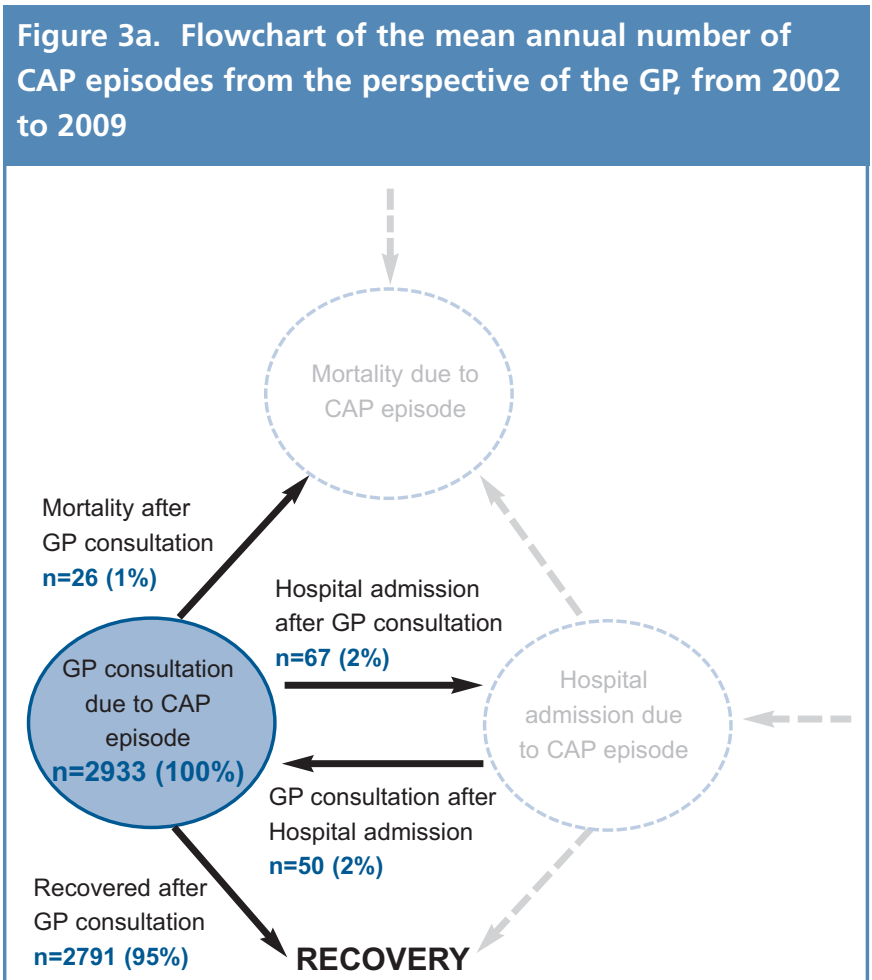

Footnote 1: Numbers (and percentages) may not add up to the total number (\%) in the blue circle due to rounding figures of the annual means.

Footnote 2: CAP episodes exclusively managed by the GP: 2791 / $(2933-50)=97 \%$ using GP practice, hospital and mortality statistics by individual data linkage. Our results show that the majority (79\%) of new CAP episodes were registered at the GP level and that $97 \%$ of these episodes were exclusively managed by the GP (i.e. the outcome was recovery without hospital admission or death). This shows that GPs have an important role in the control of CAP and efficient management of the large majority of CAP patients in the Netherlands. Most of the hospitalised CAP patients were admissions without a GP referral. This could be due to patients with very severe acute pneumonia who had to be admitted directly through emergency room facilities, or patients already known in hospital who therefore inclined to self-referral, or patients successfully choosing to bypass the GP gate-keeper. Hospitalised patients with a CAP episode were older, and it is therefore likely that they suffer more from other (severe) underlying (respiratory) diseases.

Figure 3b. Flowchart of the mean annual number of CAP episodes from the perspective of hospital admissions, from 2002 to 2009

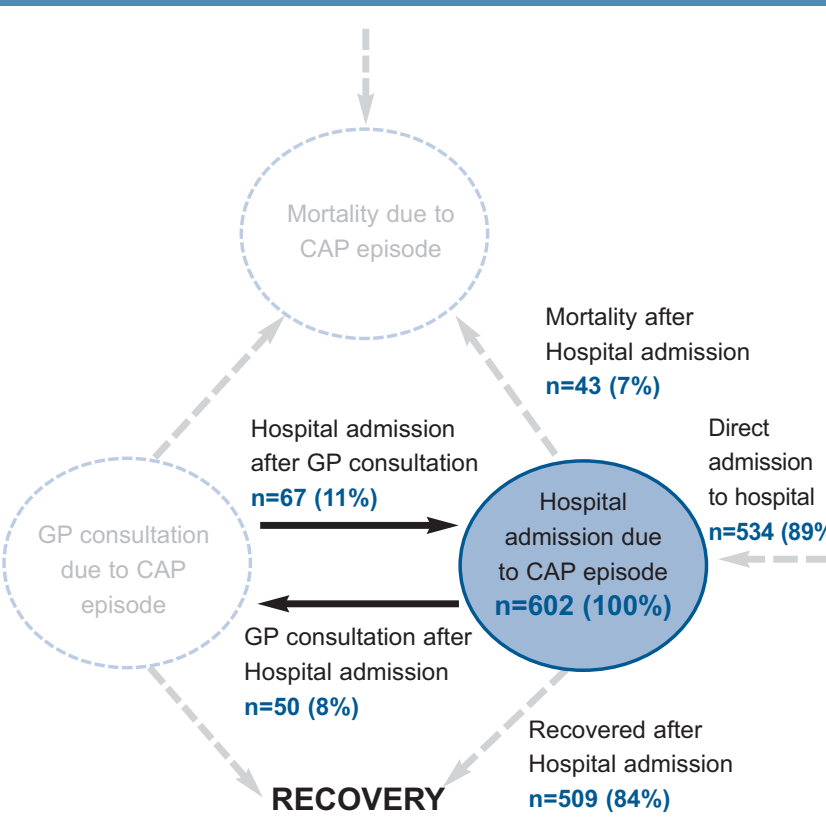

Footnote: Numbers (and percentages) may not add up to the total number (\%) in the blue circle due to rounding figures of the annual means. 
Figure 3c. Flowchart of the mean annual number of CAP episodes from the perspective of mortality, from 2002 to 2009

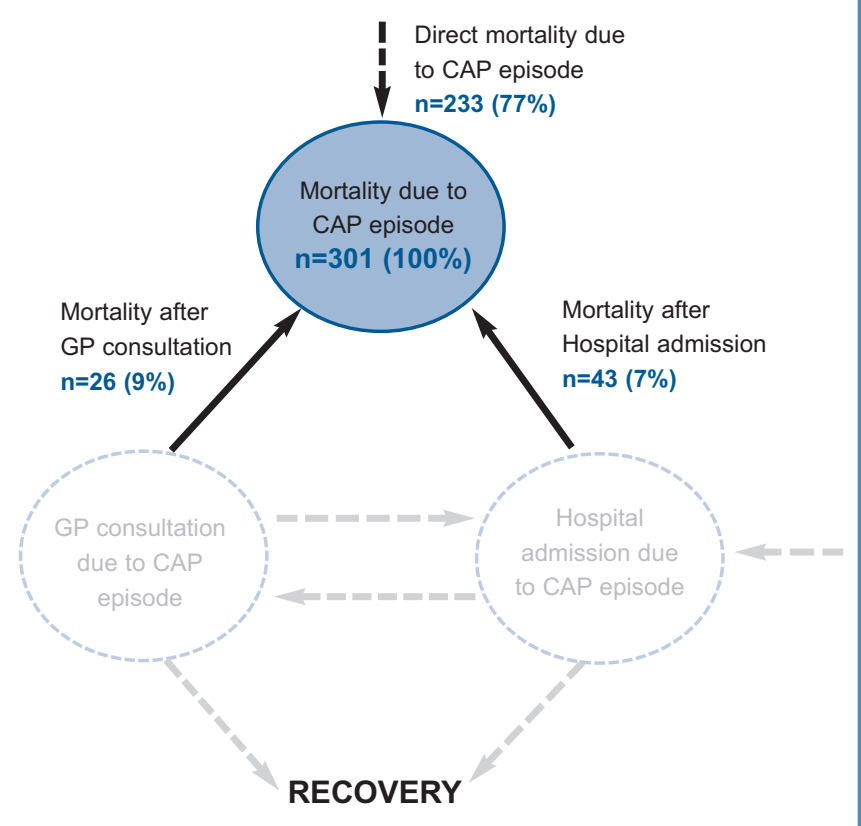

Footnote: Numbers (and percentages) may not add up to the total number $(\%)$ in the blue circle due to rounding figures of the annual means.

The majority of CAP episodes (77\%) registered in the cause of death registry were not previously registered in the GP or hospital database. These patients could also suffer from co-morbidities and account for $6 \%(233 / 3,700)$ of the total number of mean CAP episodes per year.

\section{Strengths and limitations of this study}

The strength of the study is that we could analyse CAP episodes by means of record linkage between three databases at the individual level. Our findings confirm that CAP is a highly prevalent public health problem. In the period from 2002 to 2009 the annual incidence of CAP in the Netherlands remained constant (range 70-77 per 10,000), with the year 2005 as an outlier (95 per 10,000). The increase in CAP incidence in 2005 could be related to the relatively high incidence of influenza in the season of 2004-2005 since pneumonia is a well-recognised and common complication of influenza infection. ${ }^{13}$

Our study also has some limitations. A GP diagnosis of CAP is based on clinical symptoms and is mostly not confirmed by the presence of infiltrative abnormalities on the chest x-ray or laboratory diagnosis. ${ }^{1}$ This implies that we were not able to distinguish between suspected or definite CAP. However, as GPs in the Netherlands have a gate-keeping role, the Dutch guideline recommends treatment of CAP based on a clinical diagnosis. ${ }^{1}$ Chest x-rays in the Netherlands are advised in cases of unclear diagnosis, insufficient recovery of the patient, or in those where there is a suspicion of, for example, tuberculosis or malignancy. ${ }^{1}$ However, it should be noted that a recent study showed that the majority of radiographic pneumonia diagnoses were not suspected on clinical grounds by a GP. ${ }^{14}$ Although the clinical and public health significance of such missed diagnoses are not clear, this might have led to an underestimation of the proportion of CAP episodes managed by the GP. The GP's diagnosis of pneumonia in the current study was based on registered codes (ICPC) and misclassification of some patients presenting with respiratory symptoms may have occurred. Furthermore, we did not consider information about co-morbidity, making it impossible to distinguish patients with chronic respiratory diseases such as chronic obstructive pulmonary disease.

For the definitions of CAP in the hospital discharge database and the mortality database, we used principal or secondary diagnoses of pneumonia defined by the ICD-9 and ICD-10 codes. It has previously been reported that ICD codes showed modest sensitivity (72\%) for detecting CAP, ${ }^{15,16}$ so it is likely that part of the CAP cases were also undetected in both the hospital and mortality database.

In more than $80 \%$ of hospital admissions for CAP the aetiological agent remained unknown and the discharge diagnosis was simply "pneumonia, organism unspecified" (Appendix 1). This also applies to cause of death statistics (Appendix 2). In this study, nosocomial infections could not be distinguished from community acquired infections. However, since the discharge diagnoses registered in the hospital discharge data are likely to represent the reason for hospital admission, it is unlikely that many of these diagnoses have been misclassified. However, if one or more of the hospital CAP cases were in fact nosocomial pneumonia, this implies we may have underestimated the role of the GP in the management of CAP and may have overestimated mortality from hospital CAP.

It is known that part of the study population (average of $25 \%$ in 2002-2009) could not be uniquely linked with either the hospital data or mortality data. This is considerable but common if a unique identifier number is based on date of birth and postal code and gender. However, first-generation immigrants (unknown date of birth) and students (unknown postal code) may be under-represented in our study population, but it is unlikely that these populations account for differential misclassification. Furthermore, there is a lack of information about differences in referral practices between GPs affiliated with the Netherlands Information Network of General Practice (LINH) and other GPs. CAP episodes may be underestimated in the hospital discharge register due to non-response (i.e. about $10 \%$ as a percentage of all discharges). ${ }^{9}$

Finally, in the Netherlands, CAP in institutionalised elderly people is generally treated by a nursing home physician rather than by a GP. ${ }^{17}$ We had no data available for this specific group of institutionalised patients and were not able to determine the pathways of CAP patients between nursing homes and primary healthcare, hospitalisations, and mortality. This group of patients could have been misclassified as direct admissions or direct mortality due to a CAP episode.

\section{Interpretation of findings in relation to previously published work}

During the last decade many studies have focused on a rising incidence of hospitalised pneumonia combined with persistently high mortality rates. $^{3,6,18,19}$ In an earlier population-based study we showed that 
focusing only on hospitalisations might underestimate the total public health burden of CAP. ${ }^{5}$ limitation of this previous ecological study was the use of three different datasets whereby episodes of individuals could not be linked. In the current study we were able to demonstrate after individual linkage that most CAP episodes were not only registered but were also successfully managed by a GP. To the best of our knowledge, no other studies addressing the contribution of the GP in the management of CAP using an individually linked dataset have yet been published.

\section{Implications for future research, policy and practice} To gain a better understanding of the public health burden of CAP, future studies should include CAP registered by a GP. Especially in countries like the Netherlands where GPs have a gate-keeping role, focusing on hospitalisation and mortality only conceals the large and successful contribution of GPs in the management of CAP. Record linkage at the individual level is a valuable method of elucidating the pathways of disease episodes between GP practices, hospitals, and the national death registration. It would be relevant to investigate other diseases with an unknown but presumably large public health burden in a similar fashion.

With the emergence of the pandemic influenza $A(\mathrm{H} 1 \mathrm{~N} 1)$ pdm09, the World Health Organization and European Centre for Disease Prevention and Control have highlighted the importance of establishing surveillance systems to monitor the epidemiology of severe influenza and severe acute respiratory disease in parallel with the surveillance in primary care. In the current study we have shown that CAP episodes in a primary care setting and in hospitals would largely capture different groups.

\section{Conclusions}

We conclude that, in the Netherlands, the contribution of GPs to the management of CAP patients has been underestimated. As the gatekeepers of specialised care in the Netherlands, GPs are highly successful in the management of most CAP patients and have a key role in reducing the public health burden of CAP. The causative organism is often unknown, even in hospitalised or deceased CAP patients. This raises the question of the extent to which there is a need and prospect for improved diagnosis to reduce the diagnostic deficit of CAP, with the overall aim of reducing CAP-related morbidity and mortality.

\section{Handling editor Mike Thomas \\ Statistical review Gopal Netuveli}

Acknowledgements We thank Albert Wong of the Department of Statistics, Mathematical Modelling and Data Logistics (National Institute for Public Health and the Environment) for statistical support. We also thank Dutch Hospital Data (DHD) and Statistics Netherlands for providing data.

Conflicts of interest The authors declare that they have no conflicts of interest in relation to this article.

Contributorship Involved in study concept and design: BEPS, WvdH, IS, MABvdS, ABvGL. Providing data: IS. Statistical analysis: BEPS, ABvGL. Interpretation of the results: BEPS, WvdH, ABvGL. Drafting manuscript: BEPS. Review and approval of manuscript: BEPS, WvdH, IS, MABvdS, ABvGL

Funding Funded by the National Institute for Public Health and the Environment, Ministry of Health, Welfare and Sports in the Netherlands

\section{References}

1. Verheij ThJM, Hopstaken RM, Prins JM, et al. NHG-Standaard Acuut hoesten, eerste herziening. Huisarts Wet 2011;54(2):68-92. www.nhg.org

2. Niederman MS, Luna CM. Community-acquired pneumonia guidelines: a globa perspective. Semin Respir Crit Care Med 2012;33(3):298-310. http://dx.doi.org/ 10.1055/s-0032-1315642

3. Ochoa-Gondar O, Vila-Córcoles A, de Diego C, et al. The burden of communityacquired pneumonia in the elderly: the Spanish EVAN-65 study. BMC Pub/ Health 2008;8:222. http://dx.doi.org/10.1186/1471-2458-8-222

4. World Health Organization. Department of Health Statistics and Informatics. Estimates of death cause for the year 2008. http://www.who.int/healthinfo/global burden_disease/GBD_report_2004update_full.pdf 2008.

5. van Gageldonk-Lafeber $A B$, Bogaerts $M A H$, Verheij RA, et al. Time trends in primarycare morbidity, hospitalization and mortality due to pneumonia. Epidemiol Infect 2009;137(10):1472-8. http://dx.doi.org/10.1017/S0950268809002258

6. Hoare Z, Lim WS. Pneumonia: update on diagnosis and management. BMJ (Clin Res Ed) 2006;332(7549):1077-9. http://dx.doi.org/10.1136/bmj.332.7549.1077

7. Stirbu-Wagner I, Dorsman SA, Visscher S, et al. Landelijk Informatienetwerk Huisartsenzorg. Feiten en cijfers over huisartsenzorg in Nederland. Utrecht/Nijmegen: NIVEL/IQ, 2011. http://www.LINH.nl.

8. Lamberts $\mathrm{H}$, Wood $\mathrm{M}$. The birth of the International Classification of Primary Care (ICPC). Serendipity at the border of Lac Leman. Fam Pract 2002;19(5):433-5. http://dx.doi.org/10.1093/fampra/19.5.433

9. Dutch National Medical Register (LMR) - Prismant. Available at: http://www.prismant.nl/informatieproducten/.

10. World Health Organization. International classification of diseases. Ninth revision. Geneva: World Health Organization, 1977.

11. Statistics Netherlands. Available at: http://www.cbs.nl/

12. World Health Organization (WHO). International statistical classification of diseases and related health problems. Tenth revision. Geneva: World Health Organization, 1992

13. Driver C. Pneumonia Part 1: Pathology, presentation and prevention. $\mathrm{Br} J$ Nurs 2012:21(2):103-6.

14. Vugt SF, Verheij $T$, Jong PD, et al. Diagnosing pneumonia in patients with acute cough: clinical judgment compared to chest radiography. Eur Respir J 2013 Jan 24 [Epub ahead of print]. http://dx.doi.org/10.1183/09031936.00111012

15. van de Garde EMW, Oosterheert JJ, Bonten M, Kaplan RC, Leufkens HGM International classification of diseases codes showed modest sensitivity for detecting community-acquired pneumonia. J Clin Epidemiol 2007;60(8):834-8. http://dx.doi.org/10.1016/j.jclinepi.2006.10.018

16. Guevara RE, Butler JC, Marston BJ, Plouffe JF, File TM Jr, Breiman RF. Accuracy of ICD9-CM codes in detecting community-acquired pneumococcal pneumonia for incidence and vaccine efficacy studies. Am J Epidemiol 1999;149(3):282-9 http://dx.doi.org/10.1093/oxfordjournals.aje.a009804

17. Schols JM, Crebolder HF, van Weel C. Nursing home and nursing home physician: the Dutch experience. J Am Med Dir Assoc 2004;5(3):207-12. http://dx.doi.org/ 10.1016/S1525-8610(04)70116-4

18. Thomsen RW, Riis $A$, Norgaard $M$, et al. Rising incidence and persistently high mortality of hospitalized pneumonia: a 10-year population-based study in Denmark. J Intern Med 2006;259(4):410-17. http://dx.doi.org/10.1111/j.1365-2796. 2006.01629.x

19. Trotter CL, Stuart JM, George R, Miller E. Increasing hospital admissions for pneumonia, England. Emerg Infect Dis 2008;14(5):727-33. http://dx.doi.org/ 10.3201/eid1405.071011

Available online at http://www.thepcrj.org 
Appendix 1. List of pneumonia-related ICD-9-CM codes (International Classification of Disease 9th revision, Clinical Modification) with cumulative frequency of hospital admissions over the years 2002 to 2009

\begin{tabular}{|c|c|c|}
\hline $\begin{array}{l}\text { ICD-9-CM } \\
\text { code }\end{array}$ & Explanation & $\begin{array}{l}\text { Cumulative frequency } \\
\text { (2002 to 2009) }\end{array}$ \\
\hline 003,22 & Salmonella pneumonia & \\
\hline 011 & Pulmonary tuberculosis & \\
\hline 011,0 & Tuberculosis of lung, infiltrative & \\
\hline 011,1 & Tuberculosis of lung, nodular & \\
\hline 011,2 & Tuberculosis of lung with cavitation & \\
\hline 011,3 & Tuberculosis of bronchus & \\
\hline 011,6 & Tuberculous pneumonia & \\
\hline 011,8 & Other specified pulmonary tuberculosis & \\
\hline 011,9 & Pulmonary tuberculosis, unspecified & \\
\hline 020,3 & Primary pneumonic plague & \\
\hline 020,4 & Secondary pneumonic plague & \\
\hline 020,5 & Pneumonic, unspecified plague & \\
\hline 021,2 & Pulmonary tularemia (Bronchopneumonic tularemia) & \\
\hline 022,1 & Pulmonary anthrax (Respiratory anthrax, Wool-sorters' disease) & \\
\hline 031,0 & Pulmonary infection by Mycobacterium & $<10$ \\
\hline 052,1 & Varicella (hemorrhagic) pneumonitis & $<10$ \\
\hline 055,1 & Postmeasles pneumonia & \\
\hline 073,0 & Lobular pneumonitis due to ornithosis & $<10$ \\
\hline 112,4 & Mycoses of lung, candidal pneumonia & \\
\hline 114,0 & Primary coccidioidomycosis (pulmonary)) & \\
\hline 114,9 & Coccidioidomycosis, unspecified & \\
\hline 115,05 & Infection by Histoplasma capsulatum pneumonia & \\
\hline 115,15 & Infection by Histoplasma duboisii pneumonia & \\
\hline 115,95 & Histoplasmosis, unspecified pneumonia & \\
\hline 116,0 & Blastomycosis & \\
\hline 116,1 & Paracoccidioidomycosis & \\
\hline 117,3 & Pulmonary aspergillosis & 42 \\
\hline 130,4 & Pneumonitis due to toxoplasmosis & \\
\hline 136,3 & Pneumocystosis (due to Pneumocystis carinii and Pneumocystis jiroveci) & 30 \\
\hline 480 & Viral pneumonia & \\
\hline 480,0 & Pneumonia due to adenovirus & \\
\hline 480,1 & Pneumonia due to respiratory syncytial virus & 101 \\
\hline 480,2 & Pneumonia due to parainfluenza virus & $<10$ \\
\hline 480,3 & Pneumonia due to SARS-associated coronavirus & \\
\hline 480,8 & Pneumonia due to other virus not elsewhere classified & 11 \\
\hline 480,9 & Viral pneumonia, unspecified & 53 \\
\hline 481 & Pneumococcal pneumonia [Streptococcus pneumoniae pneumonia] & 517 \\
\hline 482 & Other bacterial pneumonia & \\
\hline 482,0 & Pneumonia due to Klebsiella pneumoniae & 31 \\
\hline 482,1 & Pneumonia due to Pseudomonas & 51 \\
\hline 482,2 & Pneumonia due to Hemophilus influenzae & 106 \\
\hline 482,3 & Pneumonia due to Streptococcus & 92 \\
\hline 482,30 & Pneumonia due to Streptococcus, unspecified & \\
\hline 482,31 & Pneumonia due to Streptococcus Group A & \\
\hline 482,32 & Pneumonia due to Streptococcus Group B & \\
\hline 482,39 & Pneumonia due to other Streptococcus & \\
\hline 482,4 & Pneumonia due to Staphylococcus & \\
\hline 482,40 & Pneumonia due to Staphylococcus, unspecified & \\
\hline
\end{tabular}


Appendix 1. List of pneumonia-related ICD-9-CM codes (International Classification of Disease 9th revision, Clinical Modification) with cumulative frequency of hospital admissions over the years 2002 to 2009 continued

\begin{tabular}{|c|c|c|}
\hline $\begin{array}{l}\text { ICD-9-CM } \\
\text { code }\end{array}$ & Explanation & $\begin{array}{l}\text { Cumulative frequency } \\
\text { (2002 to 2009) }\end{array}$ \\
\hline 482,41 & Methicillin susceptible pneumonia due to Staphylococcus aureus & \\
\hline 482,42 & Methicillin resistant pneumonia due to Staphylococcus aureus & \\
\hline 482,49 & Other Staphylococcus pneumonia & \\
\hline 482,8 & Pneumonia due to other specified bacteria & \\
\hline 482,81 & $\begin{array}{l}\text { Pneumonia due to other specified bacteria: Anaerobes, Gram-negative anaerobes, } \\
\text { Bacteroides (melaninogenicus) }\end{array}$ & \\
\hline 482,82 & Pneumonia due to other specified bacteria: Escherichia coli [E. coli] & \\
\hline 482,83 & $\begin{array}{l}\text { Pneumonia due to other specified bacteria: Other gram-negative bacteria } \\
\text { Gram-negative pneumonia NOS, Proteus, Serratia marcescens }\end{array}$ & \\
\hline 482,84 & Pneumonia due to other specified bacteria: Legionnaires' disease & \\
\hline 482,89 & Pneumonia due to other specified bacteria: Other specified bacteria & \\
\hline 482,9 & Bacterial pneumonia unspecified & 72 \\
\hline 483 & Pneumonia due to other specified organism & 111 \\
\hline 483,0 & $\begin{array}{l}\text { Pneumonia due to other specified organism: Mycoplasma pneumonia } \\
\text { Eaton's agent, Pleuropneumonia-like organisms [PPLO] }\end{array}$ & \\
\hline 483,1 & Pneumonia due to other specified organism: Chlamydia & \\
\hline 483,8 & Pneumonia due to other specified organism: Other specified organism & \\
\hline 484 & Pneumonia in infectious diseases classified elsewhere & \\
\hline 484,1 & Pneumonia in cytomegalic inclusion disease & \\
\hline 484,3 & Pneumonia in whooping cough & \\
\hline 484,5 & Pneumonia in anthrax & \\
\hline 484,6 & Pneumonia in aspergillosis & $<10$ \\
\hline 484,7 & Pneumonia in other systemic mycoses & \\
\hline 484,8 & Pneumonia in other infectious diseases classified elsewhere & $<10$ \\
\hline 485 & Bronchopneumonia, organism unspecified & 216 \\
\hline 486 & Pneumonia, organism unspecified & 5875 \\
\hline 487,0 & Influenza with pneumonia & 18 \\
\hline \multirow[t]{2}{*}{$\mathrm{V} 12,61$} & Pneumonia (recurrent) & \\
\hline & TOTAL & 7350 \\
\hline
\end{tabular}


Appendix 2. List of pneumonia-related ICD-10-CM codes (International Classification of Disease 10th revision, Clinical Modification) with cumulative frequencies of deaths over the years 2002 to 2009

\begin{tabular}{|c|c|c|}
\hline $\begin{array}{l}\text { ICD-10-CM } \\
\text { code }\end{array}$ & Explanation & $\begin{array}{l}\text { Cumulative frequency } \\
\text { (2002 to 2009) }\end{array}$ \\
\hline A15 & Respiratory tuberculosis, bacteriologically and histologically confirmed & \\
\hline A15.0 & Tuberculosis of lung, confirmed by sputum microscopy with or without culture & \\
\hline A15.1 & Tuberculosis of lung, confirmed by culture only & \\
\hline A15.2 & Tuberculosis of lung, confirmed histologically & \\
\hline A15.3 & Tuberculosis of lung, confirmed by unspecified means & \\
\hline A15.4 & Tuberculosis of intrathoracic lymph nodes, confirmed bacteriologically and histologically & \\
\hline A15.5 & Tuberculosis of larynx, trachea and bronchus, confirmed bacteriologically and histologically & \\
\hline A15.6 & Tuberculous pleurisy, confirmed bacteriologically and histologically & \\
\hline A15.7 & Primary respiratory tuberculosis, confirmed bacteriologically and histologically & \\
\hline A15.8 & Other respiratory tuberculosis, confirmed bacteriologically and histologically & \\
\hline A15.9 & Respiratory tuberculosis unspecified, confirmed bacteriologically and histologically & \\
\hline A16 & Respiratory tuberculosis, not confirmed bacteriologically or histologically & \\
\hline A16.0 & Tuberculosis of lung, bacteriologically and histologically negative & \\
\hline A16.1 & Tuberculosis of lung, bacteriological and histological examination not done & \\
\hline $\bar{A} 16.3$ & $\begin{array}{l}\text { Tuberculosis of intrathoracic lymph nodes, without mention of bacteriological or } \\
\text { histological confirmation }\end{array}$ & \\
\hline A16.4 & $\begin{array}{l}\text { Tuberculosis of larynx, trachea and bronchus, without mention of bacteriological or } \\
\text { histological confirmation }\end{array}$ & \\
\hline A16.5 & Tuberculous pleurisy, without mention of bacteriological or histological confirmation & \\
\hline A16.7 & Primary respiratory tuberculosis without mention of bacteriological or histological confirmation & \\
\hline A16.8 & Other respiratory tuberculosis, without mention of bacteriological or histological confirmation & \\
\hline A16.9 & $\begin{array}{l}\text { Respiratory tuberculosis unspecified, without mention of bacteriological or } \\
\text { histological confirmation }\end{array}$ & $<10$ \\
\hline A48.1 & Legionnaires' disease & $<10$ \\
\hline A70 & Chlamydia psittaci infection & \\
\hline A78 & Q fever & \\
\hline $\mathrm{J} 11.0$ & Influenza with pneumonia, virus not identified & $<10$ \\
\hline $\mathrm{J12}$ & Viral pneumonia, not elsewhere classified & \\
\hline $\mathrm{J12.0}$ & Adenoviral pneumonia & \\
\hline $\mathrm{J} 12.1$ & Respiratory syncytial virus pneumonia & \\
\hline $\mathrm{J} 12.2$ & Parainfluenza virus pneumonia & \\
\hline $\mathrm{J12.3}$ & Human metapneumovirus pneumonia & \\
\hline $\mathrm{J12.8}$ & Other viral pneumonia & $<10$ \\
\hline $\mathrm{J} 12.9$ & Viral pneumonia, unspecified & $<10$ \\
\hline $\mathrm{J13}$ & Pneumonia due to Streptococcus pneumoniae & \\
\hline $\mathrm{J14}$ & Pneumonia due to Haemophilus influenzae & \\
\hline $\mathrm{J15}$ & Bacterial pneumonia, not elsewhere classified & \\
\hline $\mathrm{J} 15.0$ & Pneumonia due to Klebsiella pneumoniae & \\
\hline $\mathrm{J} 15.1$ & Pneumonia due to Pseudomonas & $<10$ \\
\hline $\mathrm{J} 15.2$ & Pneumonia due to Staphylococcus & \\
\hline $\mathrm{J15.3}$ & Pneumonia due to Streptococcus, group B & \\
\hline $\mathrm{J} 15.4$ & Pneumonia due to other streptococci & $<10$ \\
\hline$\underline{\mathrm{J} 15.5}$ & Pneumonia due to Escherichia coli & \\
\hline $\mathrm{J} 15.6$ & Pneumonia due to other aerobic Gram-negative bacteria & \\
\hline $\mathrm{J15.7}$ & Pneumonia due to Mycoplasma pneumoniae & $<10$ \\
\hline $\mathrm{J} 15.8$ & Other bacterial pneumonia & \\
\hline $\mathrm{J} 15.9$ & Bacterial pneumonia, unspecified & $<10$ \\
\hline $\mathrm{J16}$ & Pneumonia due to other infectious organisms, not elsewhere classified & \\
\hline
\end{tabular}


Appendix 2. List of pneumonia-related ICD-10-CM codes (International Classification of Disease 10th revision, Clinical Modification) with cumulative frequencies of deaths over the years 2002 to 2009 continued

\begin{tabular}{|c|c|c|}
\hline $\begin{array}{l}\text { ICD-10-CM } \\
\text { code }\end{array}$ & Explanation & $\begin{array}{l}\text { Cumulative frequency } \\
\text { (2002 to 2009) }\end{array}$ \\
\hline $\mathrm{J} 16.0$ & Chlamydial pneumonia & \\
\hline $\mathrm{J16.8}$ & Pneumonia due to other specified infectious organisms & \\
\hline $\mathrm{J17}$ & Pneumonia in diseases classified elsewhere & \\
\hline $\mathrm{J17.0}$ & Pneumonia in bacterial diseases classified elsewhere & $<10$ \\
\hline $\mathrm{J17.1}$ & Pneumonia in viral diseases classified elsewhere & $<10$ \\
\hline $\mathrm{J17.2}$ & Pneumonia in mycoses & $<10$ \\
\hline $\mathrm{J17.3}$ & Pneumonia in parasitic diseases & $<10$ \\
\hline $\mathrm{J} 17.8$ & Pneumonia in other diseases classified elsewhere & \\
\hline $\mathrm{J18}$ & Pneumonia, organism unspecified & \\
\hline $\mathrm{J18.0}$ & Bronchopneumonia, unspecified & 107 \\
\hline $\mathrm{J18.1}$ & Lobar pneumonia, unspecified & $<10$ \\
\hline $\mathrm{J} 18.2$ & Hypostatic pneumonia, unspecified & \\
\hline $\mathrm{J18.8}$ & Other pneumonia, organism unspecified & \\
\hline $\mathrm{J} 18.9$ & Pneumonia, unspecified & 2226 \\
\hline \multirow[t]{2}{*}{$\mathrm{J} 85.1$} & Abscess of lung with pneumonia & \\
\hline & TOTAL & 2385 \\
\hline
\end{tabular}

